\title{
Microempreendedor individual catarinense: uma análise descritiva do perfil dos empreendedores individuais em Santa Catarina
}

\begin{abstract}
RESUMO
Considerando o crescimento da representatividade de pequenos trabalhadores autônomos informais na economia brasileira e a consequente preocupação no desenvolvimento de políticas públicas que incentivem a formalização de negócios iniciantes, o presente estudo, de caráter descritivo, apresenta o perfil do microempreendedor individual catarinense e o compara aos dados nacionais. Para tal, utilizou-se a base de dados secundários disponibilizada no Portal do Empreendedor, site criado pelo governo para realização dos registros dos empresários. O estudo aponta as atividades mais comumente exercidas pelos empreendedores, bem como faixa etária, gênero e forma de atuação dessa população. A pesquisa também mostra a evolução no crescimento do número de microempreendedores individuais no estado, comparando-os ao número de empresas constituídas em outras modalidades. Conclui-se que o trabalhador autônomo informal identificou na Lei do Microempreendedor Individual uma alternativa adequada para regularizar suas atividades empresariais, ingressando na economia formal.
\end{abstract}

Palavras-chave: Microempreendedor Individual. Lei Complementar n. ${ }^{\circ}$ 128/2008. Empreendedorismo.

Christiane Mendes Drozdek Pereira christiane.pereira2006@gmail.com Mestranda da Universidade do Vale do Itajaí. Professora de Ensino Superior Everton Cordeiro Mazzoleni ecmazzoleni@yahoo.com.br 


\section{INTRODUÇÃO}

A criação da Lei Complementar no 128, de 19 de dezembro de 2008, possibilitou e incentivou trabalhadores autônomos informais a regularizarem sua situação. Segundo a referida lei, o Microempreendedor Individual (MEI) é a pessoa que trabalha por conta própria e possui, no máximo, um funcionário contratado, que recebe um salário mínimo ou o piso salarial da categoria. Além disso, para se enquadrar como Microempreendedor Individual, a pessoa não pode ter participação em outra empresa como sócio, e o seu faturamento anual não pode exceder 60 mil reais (BRASIL, 2008). A partir de 2009, influenciados pelas vantagens oferecidas pela regularização de suas atividades empresariais por intermédio do $\mathrm{MEl}$, mais de três milhões de empreendedores registraram-se no Portal do Empreendedor - a forma criada pelo governo para realização do registro (PORTAL DO EMPREENDEDOR, 2014). Entre os benefícios que incentivaram o número elevado de pessoas a buscarem a formalização, estão: (a) o registro no Cadastro Nacional de Pessoas Jurídicas (CNPJ), que possibilita a emissão de notas fiscais e credencia o microempreendedor individual a prestar serviços para empresas e participar de processos licitatórios; (b) a isenção de tributos federais, já que o microempreendedor individual recolhe mensalmente um valor fixo (entre $R \$ 34,90$ e $R \$ 39,90$ ), destinados à Previdência Social e ao ICMS ou ISS; (c) por tornar-se contribuinte da Previdência Social, o empresário enquadrado como MEI passa a ter acesso a benefícios, como auxílio maternidade, auxílio doença e aposentadoria; (d) possibilidade de acesso a serviços bancários exclusivos às empresas; (e) isenção de taxas para registro da empresa e facilidade do citado registro, pelo Portal do Empreendedor.

Como citado anteriormente, de acordo com dados do Portal do Empreendedor, até meados de junho de 2014, 4.135.855 empreendedores realizaram a sua formalização por intermédio do MEl. Entre eles estão os que se registraram diretamente como MEl, além dos Empresários Individuais, enquadrados no Simples Nacional que fizeram a opção de alteração para MEl, possibilidade concedida às empresas no início dos exercícios fiscais. Desse total de empresários, 141.092 estão estabelecidos em Santa Catarina (PORTAL DO EMPREENDEDOR, 2014).

É fato que o registro do Microempreendedor Individual oferece diversas vantagens para os empreendedores, bem como formaliza uma grande parcela da economia que estava à margem das estatísticas do governo. Por se tratar de um método de exercício de atividade empresarial relativamente recente, ainda não se tem conhecimento pleno acerca dos reflexos da formalização dessas atividades para a economia, nem sequer informações sobre os microempreendedores que buscaram a legalização.

\subsection{Objetivo Geral}

Dessa forma, o artigo tem como propósito descrever o perfil demográfico do Microempreendedor Individual (MEI) registrados no estado de Santa Catarina, no período de 2009 a 2012, por intermédio da análise de dados secundários disponibilizados no Portal do Empreendedor.

\subsection{Objetivos Específicos}

Como objetivos complementares da pesquisa, podemos citar:

a) Identificar os ramos de atuação do microempreendedor individual.

b) Conhecer a forma de atuação dos microempreendedores individuais catarinenses (se atuam em estabelecimento fixo, porta a porta, pela internet, etc.).

c) Realizar um comparativo das estatísticas nacionais com os dados do estado.

d) Analisar o perfil demográfico dos Empresários Individuais enquadrados no Simples Nacional que alteraram seu registro para Microempreendedor Individual (MEI).

e) Analisar a evolução dos registros de MEI em Santa Catarina e compará-los aos registros de empresas de outras naturezas.

Segundo Gil (1991), estudos com objetivos descritivos proporcionam uma nova visão do problema pesquisado. Assim, a descrição das informações oriundas do presente estudo, ainda desconhecidas em virtude da recente criação da Lei, pode proporcionar melhor entendimento acerca dessa nova figura representativa da economia brasileira, bem como suscitar estudos posteriores mais aprofundados a respeito do Microempreendedor Individual e sobre o impacto dessa nova modalidade empresarial na economia, o que justifica a sua realização. $\mathrm{O}$ artigo está dividido em cinco seções, além desta introdução: na primeira seção, é realizada uma abordagem teórica acerca 
do empreendedorismo. Posteriormente, é detalhado o método utilizado; na seção seguinte, são apresentados os dados e as referidas análises e, por fim, o item 5 apresenta as considerações finais do estudo.

\section{REVISÃO BIBLIOGRÁFICA}

A presente revisão de literatura objetiva levantar definições e características que abordem a importância social do empreendedorismo, bem como facilitar o entendimento das características da Lei Complementar no 128, de 19 de dezembro de 2008, que regulamenta o Microempreendedor Individual (MEI).

\subsection{O empreendedorismo}

A construção do conceito empreendedorismo, apesar de amplamente pesquisado e discutido não apresenta uma definição clara e única, pois este campo de estudo encontra-se recheado de subjetividades, dependente do contexto no qual se encontra inserido e do paradigma teórico utilizado nas pesquisas.

Um dos precursores do conceito de empreendedorismo, Richard Cantillon, via no ato de comprar e vender algo a implicação da incerteza do seu retorno (CANTILLON, 1755 apud HASHIMOTO, 2010). Say (2011) apresenta outro conceito, explicando que o empreendedorismo baseava-se na transferência de recursos de uma atividade que não gera grandes rendimentos para outra, na qual seja possível adquirir maior rentabilidade. Para isso, acreditava que os recursos de pouco valor deveriam ser transformados em algo de que as pessoas necessitassem e estivessem dispostas a pagar para adquiri-los, caracterizando um senso de busca de oportunidades. Ainda de acordo com Say, o empreendedor era um grande agente de mudanças e contribuía para com a sociedade por meio de pagamentos de impostos.

Outro pioneiro da utilização do termo foi o economista Joseph Schumpeter, que associava o empreendedorismo à inovação. Segundo ele, o empreendedor cria novas combinações a partir dos fatores de produção existentes. O progresso econômico, na sua visão, provém de atribuir novos usos a recursos já existentes, processo que denomina de inovação. Conforme Schumpeter (1928), cada produto obedece a um ciclo, que, renovado de tempos em tempos, gera novos produtos substitutos.

Abordando as características técnicas do empreendedor, Schumpeter (1949) declara que o sucesso em tirar proveito de situações favoráveis não é meramente uma questão de sorte e envolve a aptidão para a administração, a capacidade de tomar decisões rápidas e mais uma série de características, denominada por ele como uma "capacidade empresarial distinta".

Os pesquisadores Morris, Lewis e Sexton (1994) definem o empreendedorismo como uma atividade que parte de um processo gerado por entradas, identificado por oportunidades, por pessoas e pelos recursos disponíveis, e que gera retorno por meio de novos negócios, produtos, serviços, rendas e empregos. Os autores ilustraram em seu artigo de 1994, esses inputs e outputs, definidos como perspectivas sobre a natureza do empreendedorismo (Quadro 1).

Quadro 1 - Sete perspectivas sobre a natureza do empreendedorismo

\begin{tabular}{|c|c|}
\hline Criação de riqueza & $\begin{array}{l}\text { Empreendedorismo envolve assumir o risco associado em troca da produção de } \\
\text { lucro. }\end{array}$ \\
\hline $\begin{array}{l}\text { Criação do } \\
\text { empreendimento }\end{array}$ & $\begin{array}{l}\text { Empreendedorismo implica a fundação de um novo negócio investindo onde não } \\
\text { existem antecedentes. }\end{array}$ \\
\hline $\begin{array}{l}\text { Criação de } \\
\text { inovação }\end{array}$ & $\begin{array}{l}\text { Empreendedorismo preocupa-se com a combinação dos recursos que transformam } \\
\text { métodos existentes e produtos obsoletos. }\end{array}$ \\
\hline $\begin{array}{l}\text { Criação de } \\
\text { mudança }\end{array}$ & $\begin{array}{l}\text { Empreendedorismo envolve criar mudanças ajustando, adaptando e modificando } \\
\text { uma abordagem pessoal, e competência para atender a diferentes oportunidades } \\
\text { em um ambiente. }\end{array}$ \\
\hline $\begin{array}{l}\text { Criação de } \\
\text { empregos }\end{array}$ & $\begin{array}{l}\text { Empreendedorismo é a preocupação com emprego, gerenciamento e } \\
\text { desenvolvimento e fatores de produção, incluindo força de trabalho. }\end{array}$ \\
\hline Criação de valor & $\begin{array}{l}\text { Empreendedorismo é um processo de criação de valor para cliente por intermédio } \\
\text { da exploração de oportunidades inexploradas. }\end{array}$ \\
\hline
\end{tabular}


Criação de crescimento
Empreendedorismo é definido como uma força e orientação positiva em direção ao crescimento em vendas, renda, avaliação e emprego.

Fonte: Adaptado de Morris, Lewis e Sexton (1994, p. 22 )

Complementando seus estudos, os autores realizaram uma bibliométrica identificando os termos-chave utilizados nas definições de empreendedorismo, que resultou em dezoito termos. No quadro são apresentados os cinco termos mais citados nos conceitos de empreendedorismo com base no estudo bibliométrico de Morris, Lewis e Sexton (1994) - (Quadro 2).

Quadro 2 - Termos-chave sobre definições de empreendedorismo

\begin{tabular}{|c|c|}
\hline TERMOS-CHAVE & $\begin{array}{c}\text { NÚMERO DE } \\
\text { MENÇOES }\end{array}$ \\
\hline Iniciar/fundar/criar & 41 \\
\hline Novo negócio & 40 \\
\hline Inovação/novos produtos/novos mercados & 39 \\
\hline Aproveitamento de oportunidades & 31 \\
\hline Risco/incerteza & 25 \\
\hline
\end{tabular}

Fonte: Adaptado e traduzido de Morris, Lewis e Sexton (1994)

Os termos remetem claramente a uma definição de empreendedorismo que aborde a criação de novos negócios para o aproveitamento de oportunidades geradas, com base na inovação em produtos e mercados, sem desconsiderar o risco e a incerteza envolvidos, evidenciando os conceitos anteriores de Cantillon, Say e Schumpeter.

A criatividade é uma característica importante do empreendedor defendem Hamel e Prahalad (1997). De acordo com os autores, a visão estratégica do negócio permite ao empreendedor superar as limitações dos recursos, utilizando-se da criatividade para um melhor aproveitamento destes. Tal conceito é reforçado por Dornelas (2001), ao salientar que a visão do empreendedor deve ir além dos processos organizacionais e visualizar um mundo além do horizonte, pensando em sonhos e necessidades para a construção de uma sociedade melhor. $\mathrm{O}$ empreendedor deve pensar em algo que revolucione, crie, transforme, inove e que consiga transformar sonhos em realidade.

Nessa linha baseada em uma visão estratégica e de inovação, Drucker (2001) reforça a necessidade de o empreendedor estar atento às mudanças, criando novas oportunidades em mercados ainda não explorados, encontrando e explorando nichos especializados e, a partir disso, desenvolver produtos ou serviços únicos, diferenciados, que garantam a sustentabilidade do negócio.

Penrose (2006) utiliza o termo empreendedorismo para referir-se ao processo de decisão de uma firma entre expandir o seu escopo de atuação ou de simplesmente continuar suas atividades correntes. Essa análise passa logicamente, pela possível lucratividade gerada pelo crescimento da empresa.

"Esta é verdadeiramente a primeira decisão, e é provavelmente aqui que o espírito de empresa - ou um viés empresarial geral a favor do crescimento - adquire seu maior significado" (PENROSE, 2006, p. 74).

Ainda a propósito da manutenção do negócio em longo prazo, Hashimoto (2010) lembra a necessidade de o empreendedor possuir características que ampliem constantemente a sua visão. Entre elas estão: a inovação como um dos pressupostos fundamentais para transformar ideias em realidade, além de desenvolver a percepção do mercado, mantendo-se à frente dos seus concorrentes; o risco envolvido nos negócios deve fazer com que as alternativas da tomada de decisão sejam analisadas criteriosamente; e, por fim, a autonomia, para definir e decidir seus objetivos com uma base sólida que lhe permita identificar potenciais parceiros e novas oportunidades de negócios.

Características semelhantes do empreendedor já haviam sido salientadas por Hisrich, Peters e Shepherd (2009): iniciativa, organização e reorganização dos mecanismos sociais e econômicos, e o aceite do risco ou fracasso, firmando ainda mais a importância desse perfil para iniciar um negócio próprio e lhe dar continuidade.

Fiorin, Mello e Machado (2010, p. 413) afirmam que "os empreendedores tentam criar valor e fazer uma contribuição quando reconhecem uma oportunidade, um mercado a ser explorado". As autoras complementam que a criação de valor advém da inovação e da combinação dos recursos 
existentes. A inovação é fruto do perfil empreendedor e fundamental para os negócios, melhorando a eficiência, buscando a competitividade e reinventando as estratégias e os modelos de negócio. Dessa forma, essas transformações, antes de tudo, dependem da motivação do empreendedor para que ocorram constantemente em seu negócio.

A respeito da abrangência da falta de clareza acerca do conceito de empreendedorismo, Costa, Barros e Carvalho (2011), analisando o desenvolvimento do termo, esclarecem que, apesar da falta de um conceito, existem três abordagens distintas, que de forma geral podem se considerar integrantes da configuração do referido termo: a comportamental (relacionada ao perfil do empreendedor), a relacional (abordada como as competências/habilidades do empreendedor e a relação destas com a organização) e, por último, a abordagem econômica (relacionando o empreendedorismo com o fator econômico, por meio de processos de inovação e risco calculado).

Apesar de distintas, essas três abordagens fundamentam-se no ponto de vista de um mercado livre, produtor de riquezas e que necessita de indivíduos que saibam criar e aproveitar oportunidades, tornando o empreendedor peça fundamental do espírito capitalista.

\subsection{O empreendedorismo no Brasil}

Em relação ao cenário nacional, Dornelas (2001) salienta que somente a partir do período de 1990, com a abertura da economia e o surgimento de entidades como o Serviço Brasileiro de Apoio às Micro e Pequenas Empresas (SEBRAE) e a Sociedade Brasileira para Exportação de Software (SOFTEX), percebeu-se no país um movimento no sentido de incentivar a abertura de novos negócios, que passaram a contar com apoios governamentais para fomentar a sua durabilidade e competitividade.

Porém, a turbulência econômica enfrentada pelos empreendedores brasileiros até o início da década de 1990 elevou consideravelmente o número de falências de negócios iniciantes. A maior estabilidade macroeconômica dos últimos anos permitiu aos empreendedores uma maior previsibilidade, o que produziu impacto positivo sobre as condições para empreender no país. Guimarães e Azambuja (2010) e Góes et al (2013) acreditam numa perspectiva favorável para o empreendedorismo no país nos próximos anos.

Essa perspectiva otimista é confirmada por alguns dados da pesquisa "GEM - Global Entrepreneurship Monitor: Empreendedorismo no Brasil 2012". Dentre eles, podemos destacar a evolução de abertura de novos negócios demonstrada pelo aumento da Taxa Total de Empreendedorismo (quase dez pontos percentuais, comparando o período de $2002-20,9 \%$ com $2012-30,2 \%$ ), e sua relação com o aumento do PIB nesse período (4\%), obtido em grande parte devido à expansão do mercado (GEM, 2012).

Outro fator que chama a atenção relativamente à pesquisa são os "sonhos/desejos" dos respondentes em tornarem-se donos do próprio negócio (43,5\%), superando em quase $19 \%$, por exemplo, o desejo de ter uma carreira em uma empresa $(24,7 \%)$, o que podemos considerar um possível indicativo de mudança no atual modelo de mercado de trabalho.

Segundo Barros e Pereira (2008), o empreendedorismo pode ser mensurado pela atividade dos trabalhadores por conta-própria. Os autores ainda relacionam o surgimento de novas empresas com o desenvolvimento dos mercados de maneira geral, gerado pela competitividade:

\footnotetext{
A ideia é que mais entradas ou ameaças de entrada no mercado levam a mais inovação e aumento de produtividade, não somente porque estes são resultados diretos de inovações de qualidade dos novos entrantes, mas também porque a ameaça de ser desalojadas por um potencial entrante dá às empresas estabelecidas um incentivo para inovar e impedir a entrada de concorrentes (BARROS; PEREIRA, 2008, p. 983).
}

Com base nas contribuições dos autores, percebe-se que o papel do empreendedor na sociedade é de construção, pois, mediante seu empreendimento, criam-se oportunidades de geração de renda e melhoria na qualidade de vida das pessoas, por meio dos seus produtos e serviços. A circulação de renda permite melhorar a qualidade de vida das pessoas, pelo retorno à sociedade pelo recolhimento de impostos, que devem ser revertidos em saúde, educação, transporte, etc. O empreendedor cumpre uma etapa importante na manutenção dessa dinâmica social.

Diante dessa constatação da importância social do empreendedorismo, qualquer governo deve dar atenção à questão e criar situações propícias para o desenvolvimento de novos negócios. A Lei do Microempreendedor Individual busca, por intermédio da isenção de impostos federais e da desburocratização dos registros, incentivar a legalização de pequenos negócios informais. 


\title{
2.3 Microempreendedor Individual
}

A Lei do Microempreendedor Individual, como é conhecida a Lei Complementar n. ${ }^{\circ}$ 128/2008, instituiu uma diferenciação dos empresários que trabalham sozinhos ou com o auxílio de, no máximo, um empregado das demais microempresas enquadradas no Simples Nacional.

Entre os principais benefícios que a Lei proporciona ao Microempreendedor Individual estão o acesso ao Cadastro Nacional de Pessoas Jurídicas (CNPJ), a isenção de tributos federais e a desburocratização do processo. O objetivo maior da lei é incentivar a formalização de pequenos negócios que, em virtude dos custos e da burocratização, trabalhavam de forma irregular. Até junho de 2014, mais de quatro milhões de microempreendedores registraram-se em todo o país (PORTAL DO EMPREENDEDOR, 2014).

Para ter direito ao registro como MEl, o empresário individual deve enquadrar-se em algumas premissas: não ser sócio de outra empresa, não exceder a uma receita bruta anual de 60 mil reais e possuir no máximo um empregado que receba até um salário mínimo ou piso salarial da categoria. Corseuil, Neri e Ulyssea (2013, p. 32) afirmam que,

\begin{abstract}
Claramente, as mudanças introduzidas na LC no 128 influenciam diretamente as decisões de formalização daqueles que são empreendedores de pequeno porte. Não obstante, é provável que as mudanças introduzidas por essa política também tenham alterado a escolha ocupacional dos indivíduos (entre ser um microempreendedor ou um trabalhador com carteira, por exemplo), uma vez que os custos e benefícios esperados entre as diferentes opções foram alterados com a nova política.
\end{abstract}

É importante, porém, que essa nova modalidade empresarial não sirva apenas para criar estatísticas econômicas, legalizando uma parcela da economia que estava à margem dos números oficiais e tampouco seja utilizada como meios de empresas desvencilharem-se de obrigações trabalhistas, contratando Microempreendedores Individuais. Ao proporcionar a legalização de pequenos empresários informais, o governo trabalha com o sonho do pequeno empreendedor, e fornecer condições para que tais empresas sejam sustentáveis em longo prazo é fundamental.

\section{METODOLOGIA}

Este estudo, de caráter descritivo, observou e analisou aspectos dos pequenos trabalhadores autônomos informais sem, contudo, entrar no mérito dos conteúdos. A pesquisa descritiva deve expor as características de um grupo ou fenômeno, podendo estabelecer relações entre variáveis. Vergara (2000) afirma que o estudo descritivo serve de base para explicação de fenômenos, embora esse não seja seu compromisso. Segundo Gil (1991, p. 46), essas pesquisas, "embora definidas como descritivas, a partir de seus objetivos, acabam servindo mais para proporcionar uma nova visão do problema".

Para a elaboração do estudo, foram utilizados dados secundários de duas fontes distintas. A principal delas, o Portal do Empreendedor, disponibiliza informações a respeito dos registros de empresários como Microempreendedor Individual. No site http://www.portaldoempreendedor.gov. $\mathrm{br} /$, utilizado inclusive como ferramenta para registro dos microempreendedores, são disponibilizadas informações detalhadas e estatísticas a respeito dos registros desde o primeiro ano de vigência da lei. O site é mantido pela Rede Nacional para a Simplificação do Registro e da Legalização de Empresas e Negócios (Redesim), um sistema integrado que permite a abertura, fechamento, alteração e legalização de empresas em todas as Juntas Comerciais do Brasil. O órgão é administrado por um Comitê Gestor, formado por entidades do governo federal, estadual e municipal, responsáveis pelo processo de registro e legalização de empresários e sociedades empresariais. A presidência do Redesim é do Ministro do Desenvolvimento, Indústria e Comércio Exterior. Da citada fonte foram coletados, entre outros os seguintes dados:

1) Número de registros de Microempresários Individuais de julho de 2009 a junho de 2014 no Brasil e em Santa Catarina.

2) Gênero, idade, código de Classificação Nacional de Atividades Econômicas (CNAE) e forma de atuação dos Microempresários Individuais registrados.

3) Gênero, idade, código CNAE e forma de atuação das Empresas Individuais, enquadradas no Simples Nacional que requisitaram sua alteração para Microempresário Individual.

A segunda fonte de dados utilizada na pesquisa foi a Junta Comercial do Estado de Santa Catarina 
(JUCESC) que, em seu site (JUCESC, 2014), disponibiliza as estatísticas de abertura (e natureza de constituição), fechamento e alterações de empresas no estado. Foram coletadas as quantidades mensais de registros de novas empresas em Santa Catarina de julho de 2009 a dezembro de 2012.

Os dados coletados em tabelas foram analisados descritivamente por meio da técnica de medidas de posição (percentis), buscando inicialmente identificar o perfil do microempreendedor individual catarinense para, em seguida, compará-lo às estatísticas nacionais. Posteriormente, foram confrontados os números de registro de Microempreendedores Individuais com as aberturas de empresas de outra natureza no estado.

\section{ANÁLISE DOS RESULTADOS}

Desde 2009, ano em que se iniciou o registro dos Microempreendedores Individuais (MEI), até junho de 2014 foram realizadas 4.135.855 formalizações em todo o Brasil. No estado de Santa Catarina, 141.092 empreendedores realizaram o seu registro de MEl no Portal do Empreendedor.

Para dimensionar a representatividade desses números, dados da Junta Comercial do Estado de Santa Catarina (JUCESC) apontam que, no mesmo período (2009-2012), foram constituídas no estado 103.251 empresas somando-se Sociedades Anônimas, Empresas Limitadas, Cooperativas e Empresa Individual ou Empresas Individuais de Responsabilidade Limitada. Ou seja, somadas todas as formas de constituição de empresas, o montante é menor que o de Microempreendedores Individuais regularizados no período.

Evidentemente, os dados não tratam em sua totalidade, de empresas novas já que o principal intuito da criação da lei que regulamenta o Microempreendedor Individual é a legalização das atividades empresariais informais.

Desses empresários catarinenses, $53,92 \%$ são do sexo masculino e $46,08 \%$ do sexo feminino. Os dados pouco diferem da média nacional, que é de $52,58 \%$ de homens e $47,42 \%$ mulheres. Os únicos três estados em que o número de mulheres registradas no MEl supera o de homens são Alagoas (51,55\%), Ceará $(50,61 \%)$ e Espírito Santo $(50,01 \%)$.

Em relação às atividades do MEl catarinense, analisando-se os dez tipos de atividades empresariais, de acordo com o código do CNAE, que apresentam o maior número de registros de Microempreendedores Individuais em Santa Catarina, observa-se uma concentração em cinco tipos de atividades, perfazendo $42,65 \%$ do total de registros realizados: o comércio varejista de vestuário, atividades ligadas à construção civil (obras, instalação elétrica, pintura), atividades ligadas à beleza (cabeleireiros e outros tratamentos estéticos), bares, lanchonetes e similares, e confecção, conforme apresentado na tabela 1.

Tabela 1 - Dez tipos de atividade mais comuns entre os MEls de Santa Catarina

\begin{tabular}{clcc}
\hline \multirow{2}{*}{ CNAE } & \multicolumn{1}{c}{ Descrição do CNAE } & $\begin{array}{c}\text { Empresas } \\
\text { Registradas }\end{array}$ & \% do Total \\
\hline 4781400 & Comércio varejista de artigos do vestuário e acessórios & 14.360 & $10,18 \%$ \\
4399103 & Obras de alvenaria & 9.623 & $6,82 \%$ \\
9602501 & Cabeleireiros & 8.322 & $5,90 \%$ \\
5611202 & Bares e outros estabelecimentos especializados em servir & 5.735 & $4,06 \%$ \\
5611203 & Lebidas & & $2,95 \%$ \\
4321500 & Instalação e manutenção elétrica & 4.165 & $2,94 \%$ \\
9602502 & Outras atividades de tratamento de beleza & 4.145 & $2,91 \%$ \\
4330404 & Serviços de pintura de edifícios em geral & 4.110 & $2,66 \%$ \\
1412601 & Confecção de peças do vestuário, exceto roupas íntimas e & 3.759 & 3.155 \\
1412603 & Facção de peças do vestuário, exceto roupas íntimas & $2,24 \%$ \\
\hline
\end{tabular}

Fonte: Elaborado pelos autores (2014) 
Comparando esses dados às estatísticas nacionais, uma diferença observável é a diminuição da representatividade das atividades de confecção e facção em nível nacional. No estado, as duas atividades ocupam o nono e o décimo lugar entre as mais incidentes, com um total de 5.959 empresas registradas, $4,22 \%$ do total estadual. Já em nível nacional, essas atividades ocupam, respectivamente, $018^{\circ}$ e $47^{\circ}$ lugar, e representam apenas $1,67 \%$ do total de Microempreendedores Individuais registrados. Podemos associar essa divergência ao fato de o estado de Santa Catarina ser um forte polo da indústria têxtil e do vestuário em nível nacional. Dados da Federação das Indústrias do Estado de Santa Catarina (FIESC), disponibilizados no site da instituição (FIESC, 2014), apontam que o segmento do vestuário representa $17,74 \%$ da receita gerada pela indústria catarinense. Outro fato que pode ser observado na Tabela 2 é a menor concentração percentual entre os dez segmentos com o maior número de registros de empresas nas estatísticas nacionais $(38,37 \%)$ do que em Santa Catarina (42,65\%).

Tabela 2 - Dez tipos de atividade mais comuns entre os MEls do Brasil

\begin{tabular}{|c|c|c|c|}
\hline CNAE & Descrição do CNAE & $\begin{array}{c}\text { Empresas } \\
\text { Registradas }\end{array}$ & $\%$ do Total \\
\hline 4781400 & $\begin{array}{l}\text { Comércio varejista de artigos do vestuário e } \\
\text { acessórios }\end{array}$ & 444.849 & $10,76 \%$ \\
\hline 9602501 & Cabeleireiros & 300.922 & $7,28 \%$ \\
\hline 4399103 & Obras de alvenaria & 153.301 & $3,71 \%$ \\
\hline 5611203 & Lanchonetes, casas de chá, de sucos e similares & 122.688 & $2,97 \%$ \\
\hline 4712100 & $\begin{array}{l}\text { Comércio varejista de mercadorias em geral, } \\
\text { com predominância de produtos alimentícios - } \\
\text { minimercados, mercearias e armazéns }\end{array}$ & 111.353 & $2,69 \%$ \\
\hline 9602502 & Outras atividades de tratamento de beleza & 110.084 & $2,66 \%$ \\
\hline 5611202 & $\begin{array}{l}\text { Bares e outros estabelecimentos especializados em } \\
\text { servir bebidas }\end{array}$ & 100.151 & $2,42 \%$ \\
\hline 4321500 & Instalação e manutenção elétrica & 83.273 & $2,01 \%$ \\
\hline 5620104 & $\begin{array}{l}\text { Fornecimento de alimentos preparados } \\
\text { preponderantemente para consumo domiciliar }\end{array}$ & 81.601 & $1,97 \%$ \\
\hline \multirow[t]{2}{*}{4772500} & $\begin{array}{l}\text { Comércio varejista de cosméticos, produtos de } \\
\text { perfumaria e de higiene pessoal }\end{array}$ & 78.611 & $1,90 \%$ \\
\hline & Total: & 1.586 .843 & $38,37 \%$ \\
\hline
\end{tabular}

Fonte: Elaborado pelos autores (2014)

Realizando uma separação dos dez tipos de atividades empresariais mais comuns entre homens e mulheres Microempreendedores Individuais em Santa Catarina, temos o Quadro 3. 
Quadro 3 - Dez atividades mais comuns entre os MEls de Santa Catarina para homens e mulheres

\begin{tabular}{|c|l|l|}
\hline Pos. & \multicolumn{1}{|c|}{ Masculino } & \multicolumn{1}{|c|}{ Feminino } \\
\hline 1 & Obras de alvenaria & $\begin{array}{l}\text { Comércio varejista de artigos do vestuário e } \\
\text { acessórios }\end{array}$ \\
\hline 2 & Instalação e manutenção elétrica & Cabeleireiros \\
\hline 3 & Serviços de pintura de edifícios em geral & Outras atividades de tratamento de beleza \\
\hline 4 & $\begin{array}{l}\text { Comércio varejista de artigos do vestuário e } \\
\text { acessórios }\end{array}$ & $\begin{array}{l}\text { Confecção de peças do vestuário, exceto roupas } \\
\text { íntimas e as confeccionadas sob medida }\end{array}$ \\
\hline 5 & $\begin{array}{l}\text { Bares e outros estabelecimentos especializados } \\
\text { em servir bebidas }\end{array}$ & $\begin{array}{l}\text { Bares e outros estabelecimentos especializados } \\
\text { em servir bebidas }\end{array}$ \\
\hline 6 & Lanchonetes, casas de chá, de sucos e similares & $\begin{array}{l}\text { Facção de peças do vestuário, exceto roupas } \\
\text { ítimas }\end{array}$ \\
\hline 7 & Cabeleireiros & Lanchonetes, casas de chá, de sucos e similares \\
\hline 8 & $\begin{array}{l}\text { Serviços de lavagem, lubrificação e polimento } \\
\text { de veículos automotores }\end{array}$ & $\begin{array}{l}\text { Confecção, sob medida, de peças do vestuário, } \\
\text { exceto roupas íntimas }\end{array}$ \\
\hline 9 & $\begin{array}{l}\text { Reparação e manutenção de computadores e } \\
\text { de equipamentos periféricos }\end{array}$ & $\begin{array}{l}\text { Fornecimento de alimentos preparados prepon- } \\
\text { derantemente para consumo domiciliar }\end{array}$ \\
\hline 10 & $\begin{array}{l}\text { Serviços de manutenção e reparação mecânica } \\
\text { de veículos automotores }\end{array}$ & $\begin{array}{l}\text { Comércio varejista de mercadorias em geral, } \\
\text { com predominância de produtos alimentícios - } \\
\text { minimercados, mercearias e armazéns }\end{array}$ \\
\hline
\end{tabular}

Fonte: Elaborado pelos autores (2014)

O Quadro 3, demonstra uma clara diferença entre as atividades empresariais exercidas por homens e mulheres, tanto que, dos dez tipos de empresas listadas, apenas quatro repetem-se para ambos os sexos. Na coluna dos Microempreendedores masculinos, observa-se uma maior incidência de empresas relacionadas à manutenção de veículos, computadores e elétrica, além de obras de alvenaria. Já na coluna feminina, observa-se a forte incidência da confecção e facção, além do comércio varejista de mercadorias em geral e o fornecimento de alimentos preparados.

A faixa etária com maior número de Microempreendedores Individuais registrados em Santa Catarina é a dos 31 aos 40 anos, com 46.137 empresários (32,70\%). Em segundo lugar, as faixas mais representativas são dos 21 aos 30 anos (27,51\%) e dos 41 aos 50 anos (22,13\%). As demais faixas etárias somadas representam apenas $17,66 \%$ do total de empresários, embora vale ressaltar a existência de 57 microempreendedores entre 16 e 17 anos e 874 acima dos 70 anos de idade.

Outra informação disponibilizada nas estatísticas do Portal do Microempreendedor é a forma de atuação das empresas registradas. Dos 141.092 Microempreendedores Individuais catarinenses, $56,62 \%$ atuam com estabelecimento fixo para atendimento ao público. É expressivo o percentual de empresários que atuam com vendas porta em porta ou de forma ambulante (23,43\%). A atuação exclusivamente pela internet ainda possui uma baixa representatividade, com 6,89\% das empresas. As demais formas de atuação listadas (em local fixo sem loja, televendas, correios e máquinas automáticas) somadas representam os $13,08 \%$ das empresas restantes.

A pesquisa ainda buscou identificar o ramo de atuação das empresas constituídas como Empresa Individual, enquadradas no Simples Nacional e que fizeram a opção para migração para o Microempreendedor Individual, possibilidade concedida às empresas que se enquadrem nas faixas de faturamento e demais exigências do programa MEl. Das 3.367 empresas que fizeram a migração para o Microempreendedor Individual em Santa Catarina, os dez ramos de atuação de acordo com o CNAE mais incidentes na lista podem ser visualizados na Tabela 3. 
Tabela 3 - Dez tipos de atividade mais comuns entre os Empresários Individuais enquadrados no Simples Nacional que solicitaram alteração para MEI

\begin{tabular}{|c|c|c|c|}
\hline CNAE & Descrição CNAE & $\begin{array}{l}\text { Total de } \\
\text { Optantes }\end{array}$ & $\%$ do Total \\
\hline 4781400 & Comércio varejista de artigos do vestuário e acessórios & 391 & $11,61 \%$ \\
\hline 5611203 & Lanchonetes, casas de chá, de sucos e similares & 310 & $9,21 \%$ \\
\hline 5611202 & $\begin{array}{l}\text { Bares e outros estabelecimentos especializados em servir } \\
\text { bebidas }\end{array}$ & 254 & $7,54 \%$ \\
\hline 4712100 & $\begin{array}{l}\text { Comércio varejista de mercadorias em geral, com } \\
\text { predominância de produtos alimentícios - minimercados, } \\
\text { mercearias e armazéns }\end{array}$ & 205 & $6,09 \%$ \\
\hline 4520001 & $\begin{array}{l}\text { Serviços de manutenção e reparação mecânica de } \\
\text { veículos automotores }\end{array}$ & 85 & $2,52 \%$ \\
\hline 4723700 & Comércio varejista de bebidas & 82 & $2,44 \%$ \\
\hline 4530703 & $\begin{array}{l}\text { Comércio a varejo de peças e acessórios novos para } \\
\text { veículos automotores }\end{array}$ & 72 & $2,14 \%$ \\
\hline 1412601 & $\begin{array}{l}\text { Confecção de peças do vestuário, exceto roupas íntimas e } \\
\text { as confeccionadas sob medida }\end{array}$ & 63 & $1,87 \%$ \\
\hline 9602501 & Cabeleireiros & 63 & $1,87 \%$ \\
\hline \multirow[t]{2}{*}{5611201} & $\begin{array}{l}\text { Comércio varejista de outros produtos não especificados } \\
\text { anteriormente }\end{array}$ & 52 & $1,54 \%$ \\
\hline & Total & 1.577 & $46,84 \%$ \\
\hline
\end{tabular}

Fonte: Elaborado pelos autores (2014)

As 1.577 empresas da Tabela 6 representam 46,84\% das empresas já constituídas que optaram pela migração para o MEI no fim de um exercício contábil. Observa-se uma grande incidência de empresas do comércio varejista, seja de alimentos (minimercados, mercearias e armazéns), vestuário ou bebidas e lanches. Essas empresas, de pequeno porte, buscam com a migração para o MEl uma forma menos onerosa de manterem-se legalizadas.

No que diz respeito à faixa etária dos empresários que fizeram tal opção, embora os que possuam de 61 a 70 anos e mais de 70 anos representem apenas $12,27 \%$ do total de microempreendedores individuais de Santa Catarina, a representatividade desse grupo entre as empresas que solicitaram o enquadramento no Microempreendedor Individual é de 12,98\%, fato observado também nas estatísticas nacionais, conforme representado na Tabela 4.

Tabela 4: Faixa Etária dos Empresários Individuais enquadrados no Simples que solicitaram alteração para MEl - Brasil x Santa Catarina.

\begin{tabular}{|c|c|c|c|c|c|c|}
\hline \multirow[b]{2}{*}{ Faixa Etária } & \multicolumn{2}{|c|}{ Brasil } & \multicolumn{3}{|c|}{ Santa Catarina } & \multirow[b]{2}{*}{$\begin{array}{l}\text { \% Faixa } \\
\text { Etária }\end{array}$} \\
\hline & $\begin{array}{c}\text { Número de } \\
\text { Reenquadramentos }\end{array}$ & $\begin{array}{c}\% \text { de } \\
\text { Reenquadramentos }\end{array}$ & \% Faixa Etária & $\begin{array}{c}\text { Número de } \\
\text { Reenquadramentos }\end{array}$ & $\begin{array}{c}\% \text { de } \\
\text { Reenquadramentos }\end{array}$ & \\
\hline $16-17$ & 1 & $0,00 \%$ & $0,02 \%$ & 0 & $0,00 \%$ & $0,04 \%$ \\
\hline $18-20$ & 120 & $0,00 \%$ & $1,54 \%$ & 8 & $0,01 \%$ & $1,92 \%$ \\
\hline $21-30$ & 7.586 & $0,18 \%$ & $24,53 \%$ & 360 & $0,26 \%$ & $27,51 \%$ \\
\hline $31-40$ & 19.307 & $0,47 \%$ & $32,89 \%$ & 884 & $0,63 \%$ & $32,70 \%$ \\
\hline $41-50$ & 22.614 & $0,55 \%$ & $23,73 \%$ & 977 & $0,69 \%$ & $22,13 \%$ \\
\hline $51-60$ & 17.322 & $0,42 \%$ & $13,23 \%$ & 725 & $0,51 \%$ & $11,80 \%$ \\
\hline $61-70$ & 7.398 & $0,18 \%$ & $3,41 \%$ & 317 & $0,22 \%$ & $3,28 \%$ \\
\hline Acima 70 & 2.588 & $0,06 \%$ & $0,65 \%$ & 96 & $0,07 \%$ & $0,62 \%$ \\
\hline Total & 76.936 & & & 3.367 & & \\
\hline
\end{tabular}

Fonte: Elaborado pelos autores (2014)

Quatrocentas e treze das 3.367 empresas catarinenses que solicitaram tal alteração têm proprietários com mais de 61 anos. Entre as hipóteses de explicação para tal fenômeno, cabe-se estudar se a idade avançada reduz o ímpeto do empreendedor e reflete na escolha por uma forma 
de tributação menos onerosa e para um tipo de empresa menor, com limitações de crescimento.

Por fim, buscou-se realizar uma análise longitudinal com o intuito de comparar a evolução dos registros de empresas por meio do Microempreendedor Individual, confrontado com o número de empresas registradas nos métodos tradicionais. Os dados de registro de Microempreendedores Individuais foram obtidos nas estatísticas disponibilizadas no Portal do Empreendedor. Já os dados de constituição dos demais tipos de empresas foram coletados no site da Junta Comercial do Estado de Santa Catarina (JUCESC), que disponibiliza as estatísticas de constituição de empresas no estado. Os resultados são expressos no Gráfico 1, que demonstra uma nítida evolução da abertura de firmas regulamentadas como Microempreendedor Individual, com tendência linear de crescimento.

Gráfico 1 - Evolução dos registros de MEl e de outras formas de empresas

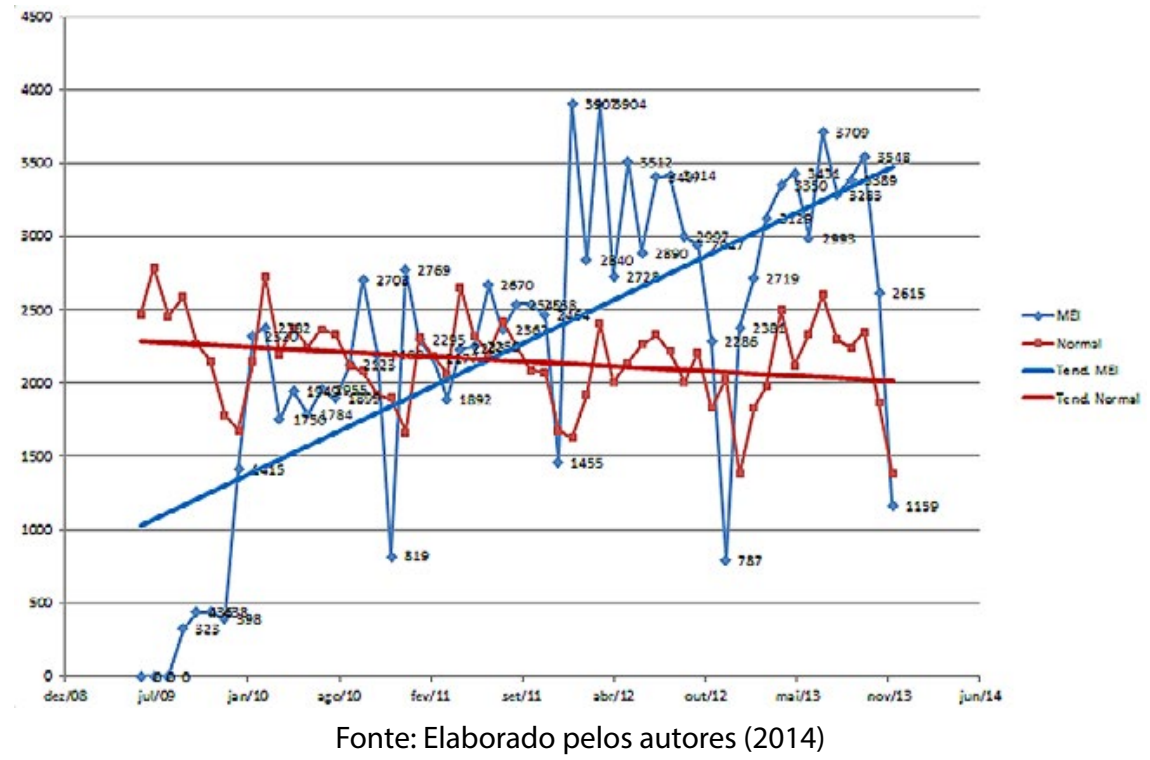

Sabe-se que as regularizações não se referem apenas a novas empresas, mas contempla igualmente a formalização de empresas que já atuavam de forma irregular e beneficiaram-se das facilidades da Lei do Microempreendedor Individual para a formalização. Por outro lado, o número de constituição de empresas, como Sociedade Limitada, Sociedade Anônima, Cooperativas ou Firmas Individuais, apresentou decréscimo nos 55 meses analisados, entre julho de 2009 e dezembro de 2013, com uma linha de tendência de redução.

\section{CONCLUSÕES}

O artigo buscou inicialmente traçar um perfil dos empresários registrados como Microempreendedor Individual em Santa Catarina de 2009 a 2013. O resultado demonstra uma pequena maioridade do sexo masculino, com $53,92 \%$ dos registros e $46,08 \%$ do sexo feminino. Com relação à faixa etária, $87,50 \%$ dos Microempreendedores Individuais catarinenses tem entre 21 e 60 anos, dados que diferem muito pouco das estatísticas nacionais. Como ramos de atuação mais incidentes, percebe-se uma diferença entre os CNAE de empresários masculinos e femininos. Dos dez CNAE de maior frequência observados entre os empresários homens, apenas quatro repetem-se entre as mulheres: Bares, Lanchonetes, Comércio de Vestuário e Cabeleireiro. As demais atividades frequentes entre os homens estão ligadas à construção civil (obras de alvenaria, pintura, manutenção elétrica e hidráulica) e a manutenção de veículos. Já, entre as mulheres, as atividades mais comuns, além daquelas que coincidem com os homens, são tratamentos de beleza, facção, confecção e comércio de alimentos (em mercearias ou prontos para consumo). Analisados conjuntamente os ramos de atividades de homens e mulheres em Santa Catarina e comparados aos dados de todo o Brasil, observa-se, em Santa Catarina, uma representatividade muito maior de atividades ligadas à indústria têxtil, como confecção de roupas, peças íntimas, facção e análogas.

No que se refere à forma de atuação, $56,62 \%$ dos Microempreendedores Individuais catarinenses atuam com estabelecimento fixo para atendimento ao público. Notou-se a expressividade do percentual de empresários que atuam com vendas porta em porta ou de forma ambulante, com 


\title{
$23,43 \%$ do total.
}

Também era objetivo do estudo analisar o perfil dos Empresários Individuais (ME) que alteraram seu registro para $\mathrm{MEl}$. O perfil destes é muito semelhante ao empresário que se registra diretamente como Microempreendedor Individual. Vale apenas ressaltar que 12,27\% dos empresários que fizeram tal opção de alteração possuem mais de 61 anos, representando essa faixa etária 9,41\% dos registros de Microempreendedores Individuais, fato que é igualmente observado nas estatísticas nacionais. Perante essa constatação, cabe estudar se a idade avançada reduz o ímpeto do empreendedor, refletindo na escolha por uma forma de tributação menos onerosa adequada para um tipo de empresa menor, com limitações de crescimento em termos de faturamento.

Conhecer o perfil do Microempreendedor Individual atuante no estado de Santa Catarina facilita futuros estudos que podem aprofundar a análise das motivações dos referidos empreendedores: se eles abrem seus negócios por oportunidade ou por necessidade (DORNELAS, 2001); se já atuavam de forma irregular e aproveitaram a oportunidade gerada pela lei do Microempreendedor Individual para formalizar a sua situação ou se são novos negócios (CORSEUIL; NERI; ULYSSEA, 2013). Pode-se, ao mesmo tempo, estudar a forma com que tais profissionais administram suas empresas a partir da formalização, reforçando Schumpeter (1949) que diminui o fator sorte e reforça a importância da "capacidade empresarial". Tais estudos podem identificar se a regularização das atividades trouxe benefícios a esses empresários.

Por fim, buscou-se confrontar os dados de aberturas de empresas em Santa Catarina, desde o advento da Lei Complementar $n^{\circ} 128$, com a evolução dos registros de Microempreendedores Individuais. Os dados demonstram um grande crescimento dos registros de MEl que inclusive superaram os de abertura de outros tipos de empresas que, por sua vez, apresentam redução. Futuros estudos podem aprofundar-se na existência de relação entre o crescimento de novos MEls e a diminuição de constituição de empresas de outra natureza, e avaliar os reflexos disso para a economia, bem como para a arrecadação tributária, visto que o MEl possui isenção de uma série de impostos que as empresas de outras naturezas recolhem.

Barros e Pereira (2008) salientam que a abertura de novas empresas faz com que os segmentos desenvolvam-se integralmente, já que, por causa dos novos entrantes que trazem inovações e o consequente aumento da concorrência, as empresas já atuantes no mercado precisam reinventarse. A regularização de 105.429 empresas em Santa Catarina que talvez não se formalizassem sem os benefícios da Lei do Microempreendedor agrega à economia e ao desenvolvimento do empreendedorismo local (CORSEUIL; NERI; ULYSSEA, 2013).

Cabe, por fim, ressaltar as limitações do presente estudo. Em razão de os dados serem disponibilizados em tabelas, perde-se a possibilidade de tratamento dos dados em softwares estatísticos a fim de buscar correlações entre variáveis e enriquecer as análises.

\section{A DESCRIPTIVE ANALYSIS OF THE PROFILE OF INDIVIDUAL MICROENTREPRENEURS (MEIS) FROM SANTA CATARINA}

\begin{abstract}
Given the growth of the representativeness of small informal self-employed workers in the Brazilian economy and the consequent concern in the development of public policies that encourage the formalization of business starters, the current study, descriptive in nature, seeks to explore and portray Santa Catarina's individual microentrepreneurs and compare them with national data. We used the basis of secondary data available on the Portal of Entrepreneurs, website created by the Brazilian government to keep the records of entrepreneurs. The study points to the activities most commonly undertaken by MEls and supplies information such as age, gender and field of action of entrepreneurs. It also presents the evolution of records of Individual Micro-entrepreneurs in the state, comparing them to the number of companies incorporated in other modalities, demonstrating that the number of MEls has grown in relation to other categories of businesses. The results demonstrate the wide acceptance of the Individual Microentrepreneur Law by the informal self-employed entrepreneurs who seem to have identified in it a good opportunity to regularize their business activities and join the formal economy.
\end{abstract}

Keywords: Individual Microentrepreneur. Supplementary Law No. 128/2008. Entrepreneurship. 


\section{REFERÊNCIAS}

BARROS, A. A.; PEREIRA, C. M. M. A. Empreendedorismo e Crescimento Econômico: uma Análise Empírica. RAC, Curitiba, v. 12, n. 4, p. 975-993, out./dez. 2008.

BRASIL. SECRETARIA DA RECEITA FEDERAL. Lei Complementar no 128, de 19 de dezembro de 2008. [2008]. Disponível em: <http://www.receita.fazenda.gov.br/LEGISLACAO/ LeisComplementares/2008/leicp128.htm>. Acesso em: 8 dez. 2014.

CORSEUIL, C. H.; NERI, M. C.; ULYSSEA, G.L. Uma análise exploratória dos efeitos da política de formalização dos microempreendedores individuais. Brasília: IPEA, 2013.

COSTA, A. M.; BARROS, D. F.; CARVALHO, J. L. F. A Dimensão Histórica dos Discursos acerca do Empreendedor e do Empreendedorismo. RAC, Curitiba, v. 15, n. 2, art.1, p. 179-197, mar./abr. 2011.

DORNELAS, J. C. A. Empreendedorismo: transformando idéias em negócios. Rio de Janeiro: Campus, 2001.

DRUCKER, P. F. O Melhor de Peter Drucker: A Administração. São Paulo: Nobel, 2001.

FIESC. Federação das Indústrias do Estado de Santa Catarina. Disponível em: <http://www.fiesc. com.br/>. Acesso em: 14 out. 2014.

FIORIN, M. M. B.; MELLO, C. M.; MACHADO, H. V. Empreendedorismo e Inovação: análise dos índices de inovação dos empreendimentos brasileiros com base nos relatórios do GEM de 2006, 2007 e 2008. Rev. Adm. UFSM, Santa Maria, v. 3, n. 3, p. 411-423, set./dez. 2010.

GIL, A. C. Como elaborar projetos de pesquisa. 3. ed. São Paulo: Atlas, 1991.

GLOBAL ENTREPRENEURSHIP MONITOR (GEM). Empreendedorismo no Brasil: Relatório Executivo. Brasília: GEM, 2012.

GÓES, A.O.S. et al. Práticas empresariais globais e locais do outro lado do Atlântico - Brasil: uma análise das entidades de fomento ao empreendedorismo. Revista da Micro e Pequena Empresa, Campo Limpo Paulista, v. 7, n. 3, p. 49-63, 2013.

GUIMARÃES, S. M. K.; AZAMBUJA, L. R. Empreendedorismo high-tech no Brasil:condicionantes econômicos, políticos e culturais. Revista Sociedade e Estado, Brasília, v. 25 n. 1, p. 93-121, jan./ abr. 2010.

HAMEL, G.; PRAHALAD, C. K. Competindo pelo futuro: Estratégias inovadoras para obter o controle do seu setor e criar as mercados de amanhã. Rio de Janeiro: Campus, 1997.

HASHIMOTO, M. Espírito empreendedor nas organizações: aumentando a competitividade através do Intraempreendedorismo. 2. ed. São Paulo: Saraiva, 2010.

HISRICH, R. D.; PETERS, M. P.; SHEPHERD, D. A. Empreendedorismo. 7. ed. Porto Alegre: Bookman, 2009.

JUCESC. Junta Comercial do Estado de Santa Catarina. Disponível em: <http://www.jucesc. sc.gov.br/>. Acesso em: 25 jun. 2014.

MORRIS, M. H.; LEWIS, P. S.; SEXTON, D. L. Reconceptualizing entrepreneuriship: an input output perspective. SAM Advanced Management Journal, Corpus Christi, TX, v. 59, n. 1, p. 21-31, 1994.

PENROSE, E. A teoria do crescimento da firma. Campinas: UNICAMP, 2006.

PORTAL DO EMPREENDEDOR. Rede Sim. Disponível em:

<http://www.portaldoempreendedor.gov.br/> Acesso em: 25 jun. 2014.

SAY, J.B. Traité d'Économie politique ou simple exposition de la manière dont se forment, se distribuent et se consomment les richesses. Paris: Institut Coppet, 2011. 
SCHUMPETER, J. The Instability of Capitalism. The Economic Journal, St. Andrews, v. 38, n. 151 p. 361-386, Sept. 1928.

SCHUMPETER, J. Economic theory and entrepreneurial history. Change and the Entrepreneur: Postulates and Patterns of Entrepreneurial History. Cambridge: Harvard University Press, 1949.

VERGARA, S. C. Projetos e relatórios de pesquisa em administração. 3. ed. São Paulo: Atlas, 2000. 